\title{
The unifying mechanism in the initiation and prevention of breast and other human cancers E Cavalieri* and E Rogan
}

\author{
Address: Eppley Institute for Research in Cancer and Allied Diseases, University of Nebraska Medical Center, Omaha, NE, USA \\ Email: E Cavalieri* - ecavalie@unmc.edu \\ * Corresponding author
}

from 6th International Symposium on the Intraductal Approach to Breast Cancer

Santa Monica, CA, USA. |9-2| February 2009

Published: 24 July 2009

BMC Proceedings 2009, 3(Suppl 5):S8 doi:10.1 I86/I753-656I-3-S5-S8

This abstract is available from: http://www.biomedcentral.com/1753-656I/3/S5/S8

(C) 2009 Cavalieri and Rogan; licensee BioMed Central Ltd.

Exposure to estrogens is a risk factor for human breast cancer. Experiments on estrogen metabolism, formation of DNA adducts, carcinogenicity, mutagenicity and cell transformation led to and support the hypothesis that reaction of specific estrogen metabolites, catechol estrogen-3,4-quinones, with DNA can generate the critical mutations to initiate breast, prostate and other human cancers. The major initiating pathway is illustrated in Figure 1. Estrone $\left(\mathrm{E}_{1}\right)$ and estradiol $\left(\mathrm{E}_{2}\right)$ can be metabolically converted to $4-\mathrm{OHE}_{1}\left(\mathrm{E}_{2}\right)$ by cytochrome P450 (CYP)1B1. Oxidation of these catechol estrogens leads to the corresponding catechol estrogen-3,4-quinones, which can react with DNA to form very small amounts of stable adducts, which remain in DNA unless removed by repair, and predominant amounts (99\%) of depurinating adducts, which detach from DNA, leaving behind apurinic sites. Errors in the repair of these sites can lead to the critical mutations that can initiate breast, prostate and other human cancers.

\section{Cancer biomarkers}

The depurinating adducts are shed from cells and tissues into the bloodstream and are excreted in urine. This allows their identification and quantification as biomarkers of risk of developing breast, prostate and other human cancers. High adduct levels have been detected in analysis of urine and serum from women that are at high risk for breast cancer or already have the disease. These analyses are conducted by using ultraperformance liquid chromatography/tandem mass spectrometry, a technology devel- oped in our laboratory. In an initial study of such women, highly significant differences were observed when urine samples from normal-risk women were compared to high-risk women or those with breast cancer. Similar results were obtained in a second, larger study of women with and without breast cancer and at high risk for the disease. In addition, analysis of urine samples from men with and without prostate cancer showed that men with the disease have relatively high levels of estrogen-DNA adducts compared to men without prostate cancer. These results have been confirmed in a second, larger study.

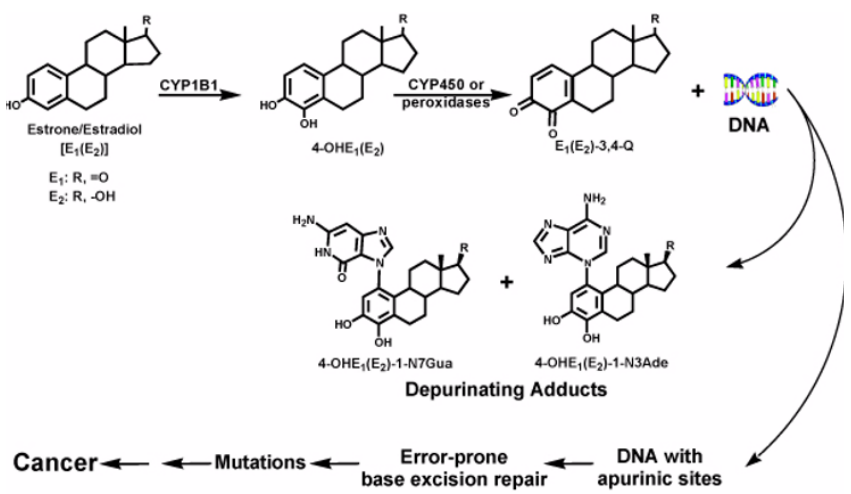

Figure I

Major metabolic pathway in cancer initiation by estrogens. 


\section{Cancer prevention}

Prevention of cancer arises from blocking the first critical step in initiation, reaction of catechol estrogen quinones with DNA. The most appropriate compounds for this task include $\mathrm{N}$-acetylcysteine (NAcCys), which blocks reaction of the quinones with DNA by reacting with the quinones and reducing the semiquinones back to catechols. In addition, NAcCys helps replenish the antioxidant glutathione in cells. Resveratrol has the same chemical properties as NAcCys in reducing the semiquinones to catechols, but also induces the protective enzyme quinone reductase and modulates the activating enzyme CYP1B1. When the MCF-10F human breast epithelial cells were cultured in the presence of $4-\mathrm{OHE}_{2}$, and resveratrol and NAcCys were added to the culture medium at different doses, the formation of estrogen-DNA adducts by the cells was greatly inhibited. These two antioxidants also inhibit the transformation of MCF-10F cells and E6 mouse mammary cells to malignant cells. The results of these studies suggest that selected natural antioxidant compounds can reduce formation of estrogen-DNA adducts, presumably decreasing the risk of initiating and, thus, developing breast, prostate and other human cancers.

Publish with Biomed Central and every scientist can read your work free of charge

"BioMed Central will be the most significant development for disseminating the results of biomedical research in our lifetime. " Sir Paul Nurse, Cancer Research UK

Your research papers will be:

- available free of charge to the entire biomedical community

- peer reviewed and published immediately upon acceptance

- cited in PubMed and archived on PubMed Central

- yours - you keep the copyright

Submit your manuscript here:

http://www.biomedcentral.com/info/publishing_adv.asp 